\title{
The Role that Affective States Play in Tertiary Level Second Language Classrooms in Bangladesh: A Private University Scenario SONIYA IRFAT URMEE
}

\begin{abstract}
Since Communicative Language Teaching has been introduced in the English classrooms of Bangladesh, we have experienced many changes. As Communicative Approach is supposed to create environment to lessen anxiety and other affective states of learners to a considerable extent, we naturally expected to find students free of the influence of these affective states in tertiary level classrooms. But the real fact is, still a large number of tertiary level second language learners in Bangladesh react to the learning situations in different affective ways. The influence of these affective states on learners' ability to concentrate on learning is immense.
\end{abstract}

This article intends to analyze the multifaceted and complex nature of learners' affective states in tertiary level second language classrooms in a private university of Bangladesh and the effects these have on learners' ability to capture input and produce output or performance. 60 major and non-major English students were selected from a leading private university of Dhaka, who had completed a questionnaire, consisting of 25 questions. The study shows that, affective states play a very strong role in L2 classrooms and most students identify the need to be stressfree and secure before they concentrate on their learning activities. The study also reveals that, speaking and listening are the skills mostly affected by the influence of affective states. Finally, this paper endeavours to offer some recommendations which I found useful in this context, to lessen or eliminate the harmful influence of learners' affective states on their second language learning.

In my paper, I have taken into consideration the students dealing with the four major skills, namely, reading, writing, speaking and listening, as these are the most practiced skills in tertiary level classrooms in Bangladesh. My recommendations 
will cover practices to be undertaken by both teachers and students, to eliminate or lessen the harmful influence of affective states on learners' concentration level and performance.

\section{Introduction}

The study on affective states has immense importance in Second Language Acquisition. 'Affective State' means the acquisition condition of the learner which is influenced by a number of factors. According to Rod Ellis:

The learner's affective state is influenced by a number of factors, for example, anxiety, a desire to compete, whether learners feel they are progressing or not. It is hypothesized that it can influence the rate of L2 acquisition and the ultimate level of achievement. (The Study 693)

Ellis also made a statement that, learners, in particulars classroom learners, react to the learning situations they find themselves in a variety of affective ways. He, however, admits that, it is not easy to study the role that affective states play in L2 learning in a systematic manner, if only because they are so individualistic and changeable (The Study 479).

To clarify the idea of affective states we need to understand the notion of the Affective Filter as proposed by Dulay and Burt, which Krashen incorporates in his Monitor Model (Natural Approach). Rod Ellis writes:

The filter controls how much input the learner comes into contact with, and how much input is converted into intake. It is 'affective' because the factors which determine its strength have to do with the learner's motivation, selfconfidence, or anxiety state. Learners with low anxiety have low filters and so obtain and let in plenty of input. Learners with low motivation, little selfconfidence, and high anxiety have high filters and so receive little input and allow even less in. (Understanding 263)

The focus of this article is to study the most common affective factors for some Bangladeshi learners who are undergraduate students of a private university in Dhaka and the influence of those affective factors in learning English. I also tried to 
find out the most affected skills by affective factors. Lastly, I listed some measures, which I found useful, on how to eliminate or lessen the harmful influence of affective factors which include practices to be undertaken by both teachers and students.

\section{Literature Review}

A series of extensive research has been conducted by Stephen D. Krashen (Principles) on the importance of motivation, self-confidence and anxiety- the three basic factors.

R. Gardner and his associates (like Gardner, 1996; 1985; 1980; 1979; Gardner and Lambert, 1972; Gardner and MacIntyre, 1993; Tremblay and Gardner, 1995) worked on the relation between motivation and second language learning. Krashen worked on the two other factors-self-confidence and anxiety-in many of his important studies (Principles, Natural Approach). A huge number of studies have been done on these issues and studies are still going on.

\section{Krashen's Affective Filter Hypothesis}

Krashen argues that, the three basic affective factors-motivation, self confidence and anxiety-are more related to achievement measured by communicative test than by formal language tests. Krashen writes:

... relationship between affective variables and the process of second language acquisition by positing that acquirers vary with respect to the strength or level of their Affective Filters. Those whose attitudes are not optimal for second language acquisition will not only tend to seek less input, but they will also have a high or strong Affective Filter even if they understand the message, the input will not reach that part of the brain responsible for language acquisition, or the language acquisition device. Those with attitudes more conducive to second language acquisition will not only seek and obtain more input, they will also have a lower or weaker filter. They will be more open to the input, and it will strike "deeper". (Principles 31)

The Affective Filter is the basic reason for people's fossilization in language 
acquisition.

Krashen writes:

... our pedagogical goals should not only include supplying comprehensible input, but also creating a situation that encourages a low filter ... . The input hypothesis and the concept of the Affective Filter define the language teacher in a new way. The effective language teacher is someone who can provide input and help make it comprehensible in a low anxiety situation. (Principles 32)

Let us now discuss the three basic factors that underlie the Affective Filter.

\section{Motivation}

Gardner and Lambert differentiates the two types of motivation. When learners are influenced by integrative motivation they will learn L2 to be an integral part of the culture of the L2 community. On the contrary, learners influenced by instrumental motivation will learn L2 for practical and functional reasons, e.g. to get good grades in exam or proficiency tests, to get a well-paid job, to migrate to other countries etc (Attitudes and Motivation).

\section{Self-Confidence}

Krashen referred to self-confidence as one of the factors that affected the affective filter. Krashen thinks self-confidence is often linked to family variables. Families displaying too strict discipline or inconsistent discipline and disapproval of children, produce adults having low self-image (Principles).

On the other hand, families having regular but not rigid routines and providing openness of discussion regarding standards of behaviour and approval of children and their friends produce confident adults (Principles).

Once again, a variety of factors are likely to affect self-confidence, from family through school to peers. Furthermore, as poor self-image can lead to poor performance, just like that, poor performance can lead to poor self-image (Principles). 


\section{Anxiety}

Anxiety is the third factor mentioned by Krashen. Psychologists distinguish between trait, state and situational anxiety. Trait anxiety is a permanent tendency to be anxious. It relates to upbringing and self-image. State anxiety is linked to a particular moment in time, within a specific situation. It may be a relational problem, like being linked to specific persons-for example, a particular teacher. The third one, situational anxiety is created by a specific type of situation or event-classroom participation, examination, public speaking etc. (Principles).

\section{The Position of English in the Education System of Bangladesh}

The national and official language of Bangladesh is Bangla. English is used mostly for functional purposes, not widely as a means of communication. The education system is divided into three sections in the country -Bangla Medium, English Medium and Madrassa system. However, at tertiary level, in public and national universities, English is not always the medium of instruction in nonEnglish major classes. But, in private universities, the scenario is opposite. Students have to submit their assignments in English, do regular class presentations in English and write exam answers in English.

\section{The Practical Usage of English}

In the private job sector, people skilled in English are getting preference. In proficiency tests like IELTS and TOEFL, English skills are required again. People who have studied or worked abroad and have settled in Dhaka, have created a community which uses English frequently in its conversations.

If we take into consideration the present condition of English language in the country, it will be easy for us to find out the affective factors influencing Bangladeshi L2 learners.

\section{Research Methodology}

\section{a) Participants}


All the participants in this study are private university undergraduate students. Private university students are chosen for being more oriented to the English Language learning environment. 60 students were randomly selected from Stamford University Bangladesh, who have either completed or are still going through the English credit courses. Among the 60 students, 20 are from English Department, 5 from Microbiology, 5 from Journalism, 5 from Law, 5 from Film and Media, 10 from the Business Administration Department, 5 from Computer Science and 5 are from Civil Engineering.

Among them, 30 are male participants and 30 female. The age range is from 1925 years. All the students are from Bangla-medium backgrounds and had English as a compulsory course in Secondary and Higher Secondary levels.

\section{b) Data Collection Process}

The survey was conducted with a questionnaire consisting of 25 questions. Question no. 1-23 were a 5 point scale format which ranged from 'strongly disagree' to 'strongly agree'. They are rated as follows:

Strongly Disagree-1, Disagree-2, Neutral-3, Agree-4, Strongly Agree-5.

Question no. 1-14 were designed to find out the nature of the students' individual affective factors.

Question no. 15-17 were designed to find out the skills which students find out to be most affected by affective states.

Question no. 18-20 were designed to find out the students' opinion on the teacher's role in lowering affective filters.

Question no. 21-23 were designed to find out the students' opinion about their own roles in lowering their affective filters.

In question no. 24, the students rated their English proficiency as very $\mathrm{bad} / \mathrm{bad} /$ average/good/very good. 
In question no. 25, the students stated if they would be capable of learning English better, if affective filters were lowered in the classrooms. Then, they tried to state the reasons by answering the open ended 'why' question.

\section{c) Results}

The survey results show that, most of the participants find classroom environment to be a major factor influencing their L2 learning. Their affective states largely depend on the classroom environment. Most of the participants also feel that teachers can play a very important role in creating positive classroom environment.

In response to question no-1, 38 participants $(63.33 \%)$ showed that they disagreed with the idea. Only 22 participants (36.66\%) agreed with the idea. In response to Q2, we find that, 48 participants $(80 \%)$ strongly agreed, 7 participants $(11.66 \%)$ agreed and 5 participants $(8.33 \%)$ disagreed with the idea. So, we find that instrumental motivation is the driving force behind most of the participants' L2 learning.

In response to Q3, 18 participants (30\%) agreed, 20 participants (33.33\%) were neutral and 22 participants (36.66\%) disagreed. In response to Q4, 45 participants (75\%) strongly agreed, 8 participants $(13.33 \%)$ agreed and only 7 participants (11.66\%) were neutral. We find no disagreement here. It proves that most of the participants think classroom environment is really important for students' better motivation level.

In response to Q5, 42 participants (70\%) strongly agreed, 10 participants $(16.66 \%)$ agreed and 8 participants $(13.33 \%)$ were neutral. It proves that most of the participants think positive evaluation leads to motivated learning.

In response to Q6, 16 participants (26.66\%) agreed, 32 participants (53.33\%) disagreed and 12 participants $(20 \%)$ were neutral. So, we can see that most of the participants think their self-image does not depend on whether they attended English or Bangla medium school. 
In response to Q7, 35 participants (58.33\%) agreed, 15 participants (25\%) were neutral and 10 participants $(16.66 \%)$ disagreed. So, we can see that better performing classmates make a large number of participants anxious about their own self-image.

In response to Q8, 42 participants (70\%) strongly agreed, 12 participants $(20 \%)$ agreed and 6 of them $(10 \%)$ were neutral. It proves most of the participants feel grades or external evaluation from teachers or peers influence their self-image.

In response to Q9, 32 participants (53.33\%) strongly agreed, 14 participants (23.33\%) agreed and 14 of them $(23.33 \%)$ were neutral. So, we find that upbringing, family support and satisfaction in personal life are important for a large number of participants to deliver their best in class.

In response to Q 10, 32 participants (53.33\%) strongly agreed and among them 25 $(41.66 \%)$ were females. 18 participants $(30 \%)$ were neutral and 10 participants $(16.66 \%)$ disagreed with the idea. It states that trait anxiety is more common in female participants and in general, trait anxiety influences the L2 learning of quite a good number of students.

In response to $\mathrm{Q} 11,44$ participants $(73.33 \%)$ strongly agreed, 11 participants $(18.33 \%)$ were neutral and 5 of them $(8.33 \%)$ disagreed.

In response to $\mathrm{Q} 12,32$ participants $(53.33 \%)$ strongly agreed, 18 participants $(30 \%)$ were neutral and 10 participants $(16.66 \%)$ disagreed. In response to Q 13, 33 participants $(55 \%)$ strongly agreed, 17 participants $(28.33 \%)$ were neutral and 10 of them $(16.66 \%)$ disagreed. In response to Q 14,31 participants $(51.66 \%)$ strongly agreed, 18 participants (30\%) disagreed and 11 participants (18.33\%) strongly disagreed. So, it proves that a very good number of participants suffer from state and situational anxieties.

In response to $Q 15,45$ participants $(75 \%)$ strongly agreed that speaking is the most-affected skill by affective states. In response to Q 16, 35 participants (58.33\%) agreed that listening is another highly affected skill by affective states. In response to $\mathrm{Q} 17$, we find that, 42 participants $(70 \%)$ agreed that reading and writing are 
relatively less affected by affective states.

In response to $\mathrm{Q} 18,19$ and 20, we find that respectively 48,45 and 38 participants $(80 \%, 75 \%$ and $63.33 \%)$ strongly agreed to the ideas. That means most participants believe, teacher's role in lowering affective filters is very important.

However, participants are not totally unaware of their own roles as students in lowering affective filters. In response to Q 21, 22 and 23, respectively 32, 43 and 31 participants $(53.33 \%, 71.66 \%$ and $51.66 \%)$ strongly agreed to the ideas. It means quite a good number of participants are conscious about their own roles in lowering affective filters.

In response to Q 24, 25 participants rated their English proficiency as average, 23 as good, 5 as bad and 7 as very good. The percentage is respectively $41.66 \%, 38.33 \%$, $8.33 \%$ and $11.66 \%$.

In answer to Q 25, 57 participants (95\%) agreed that, they will be capable of learning English better, if affective filters are lowered in the classroom. In answer to the open ended "why" question, participants came up with a number of responses:

- 32 participants (53.33\%) think that, if the classroom environment is studentfriendly, it is possible for learners to increase their concentration in learning.

- 11 participants $(18.33 \%)$ think that, classroom environment is the most important factor to lower affective filters and enhance learning, and both teachers and students should work at it.

- 14 participants $(23.33 \%)$ think that teachers play a crucial role in creating positive classroom environment.

- 3 participants (5\%) think if the students are not confident enough in using target language outside the classroom, only classroom environment cannot increase their level of proficiency.

So, we can understand that most of the participants emphasize the importance of classroom environment to lower affective filters of learners and increase their level 
of proficiency.

\section{A Few Recommendations to Lower the Affective Filters of Students in Classroom}

Here, I have listed some measures, which I found useful in tertiary level L2 class rooms, on how to eliminate or lessen the harmful influence of affective factors, which include practices to be undertaken, by both teachers and students.

In Bangladesh, the urban people get a chance to know the culture of the Englishspeaking community only through electronic media and web based social networking applications like Facebook etc. But otherwise most of the L2 learners do not find chances for direct communication with native or native-like fluent and proficient English speakers. Teachers should understand that and increase their levels of tolerance regarding students' mistakes in classroom response. They should also try to create an overall positive environment in the classroom by equal distribution of attention towards students. At least, some kind of positive evaluation should be ensured when students respond in class. It can be a positive remark at first about a part of the students' response and then the teacher can discuss the mistakes. At times, better performing classmates make some students too anxious about their self-images. Even, lack of positive evaluation from peers can make some students too conscious about their own mistakes. So, the teacher should ensure that in pair or group works and in classroom discussions, one or two bright students should not always dominate the conversation or class work. Every student should get a chance to participate and contribute to the assigned work. Although, in large classrooms and with large groups it can be little difficult, still, teachers can create opportunities for every student to contribute to the assigned work to some extent. Another factor worth mentioning is, sometimes the students are intimidated in the initial classes, if the teacher has a very good pronunciation or accent and an excellent command over the target language. So, in the initial classes, the teacher should take a little care to find out the students' level and make them feel at ease with the classroom environment. Often, on the very first day, teachers might take a diagnostic test to check the level of students and it is quite helpful. 
Sometimes the students just do not open their month due to anxiety about making silly grammatical or pronunciation mistakes. They should be assured that minor mistakes can occur and it is natural. Obviously, the teacher has a right to correct these mistakes, but if (s)he wants to create a positive environment in the class, being too critical or satirical about trifling mistakes in the initial classes can harm the purpose. In large classes, it often becomes difficult for the teacher to pay individual attention to each and every student. But, at least, (s)he can make sure that, no student feels left out and every student should consciously be encouraged by the teacher to respond and participate in classroom discussions.

This survey shows that, speaking and listening are the two highly affected skills by affective states. So, after discussion on a certain point, the teacher can ask the students questions to find out if they have grasped the idea and to check how well they can express it. This is a very useful technique to ensure better listening and speaking for the students.

However, students also should try to create positive self-images and should not hesitate to respond in the class, even if they feel that, there are better performing classmates around. While speaking, they should not be too conscious about minor grammatical and pronunciation mistakes because it can destroy the spontaneity of their speech.

In Bangladesh, when the students go out of the classroom, they lose touch with the target language and whatever they learn in the classroom, is easily forgotten due to the lack of use. Although a good number of students, who use internet and web-based networking applications, are becoming conscious about the usage of English, speaking still remains a neglected skill. Therefore, the educational institutions should ensure an English speaking environment inside the campus. The teachers also can take some helpful initiatives such as, using easy English instead of Bangla to explain something difficult in the class, using English in student counseling hours and using English whenever they communicate with students. 
Students should not always expect the classroom environment to be $100 \%$ perfect; they should rather create internal motivation in themselves to learn the target language better.

We can conclude this part by saying that both teachers and students should take measures to create positive classroom environment and ensure better learning.

\section{Conclusion}

In conclusion, it can be said that, this research has endeavoured to find out the specific affective factors which influence the L2 learning of a number of Bangladeshi tertiary level L2 learners who have come from Bangla medium schools and colleges, and to provide some practical suggestions to lower their affective filters. If we can ensure a positive learning environment to eliminate low motivation, little self-confidence and high anxiety, we will be able to create a good opportunity for English language learners coming from Bangla medium background to enhance their English skills. 


\section{Works Cited}

Dulay, H. and M. Burt. "Remarks on creativity in language acquisition." Viewpoints on English as a Second Language. Ed. M. Burt, H. Dulay, and M. Finnocchario. New York: Regents. 1977. Print.

Ellis, Rod. Understanding Second Language Acquisition. Oxford: Oxford University Press, 1985. Print.

---. The Study of Second Language Acquisition. Oxford: Oxford University Press, 1994. Print.

Gardner, R.C. and W.E. Lambert. Attitudes and Motivation in Second Language Learning. Rowley, Mass: Newbury House, 1972. Print.

Krashen, S. Principles and Practices in Second Language Acquisition. Oxford: Pergamon, 1982. Print.

Krashen, S. and T. Terrell. The Natural Approach: Language Acquisition in the Classroom. Oxford: Pergamon, 1983. Print.

\section{References}

Gardner, R.C. “Social Psychological Aspects of Second Language Acquisition." Journal of Language and Social Psychology 2 (1979): 219-239. Print.

---. “On the Validity of Affective Variables in Second Language Acquisition: Conceptual, Contextual and Statistical Considerations." Language Learning 30(1980): 255-270. Print.

---. Social Psychology and Second Language Learning: the Role of Attitudes and Motivation. London: Edward Arnold, 1985. Print.

---. "Motivation and Second Language Acquisition: Perspectives." Journal of the CAAL 18.2 (1996): 19-42. Print.

Gardner, R.C and P.D. MacIntyre. “A Students Contribution to Second Language Learning. Part II: Affective Variables." Language Teaching 26 (1993): 1-11. Print.

Tremblay, P.F. and R.C. Gardner. "Expanding the Motivation Construct in Language Learning." The Modern Language Journal 79 (1995): 505-518. Print. 


\section{Appendix}

\section{Survey Questionnaire on Affective States and English Language Learning}

Below are a number of statements with which you may agree or disagree. Please indicate your opinion by ticking the boxes below which best indicates the extent to which you agree or disagree with the statement. Your statement will be kept confidential.

Department

Gender

Age

\begin{tabular}{|c|c|c|c|c|c|}
\hline & $\begin{array}{l}\text { Strongly } \\
\text { Disagree }\end{array}$ & Disagree & Neutral & Agree & $\begin{array}{c}\text { Strongly } \\
\text { Agree }\end{array}$ \\
\hline $\begin{array}{l}\text { A. Role of Affective States in } \\
\text { Your Language of L2 } \\
\text { (i) Motivation }\end{array}$ & & & & & \\
\hline $\begin{array}{l}\text { 1. A major motivation for you to } \\
\text { learn English is, you want to } \\
\text { become a part of the English } \\
\text { speaking global community. }\end{array}$ & & & & & \\
\hline $\begin{array}{l}\text { 2. A major motivation for you to } \\
\text { learn English is, you want to get } \\
\text { a good job, grade, status and } \\
\text { such practical benefits. }\end{array}$ & & & & & \\
\hline $\begin{array}{l}\text { 3. You have to be motivated to } \\
\text { learn even before coming to the } \\
\text { class. (Background Motivation) }\end{array}$ & & & & & \\
\hline $\begin{array}{l}\text { 4. The classroom environment is } \\
\text { important for you to be } \\
\text { motivated in learn. (Classroom } \\
\text { Motivation) }\end{array}$ & & & & & \\
\hline $\begin{array}{l}\text { 5. Better grades or positive } \\
\text { evaluation leads to motivated } \\
\text { learning. }\end{array}$ & & & & & \\
\hline (ii) Self-confidence & & & & & \\
\hline
\end{tabular}




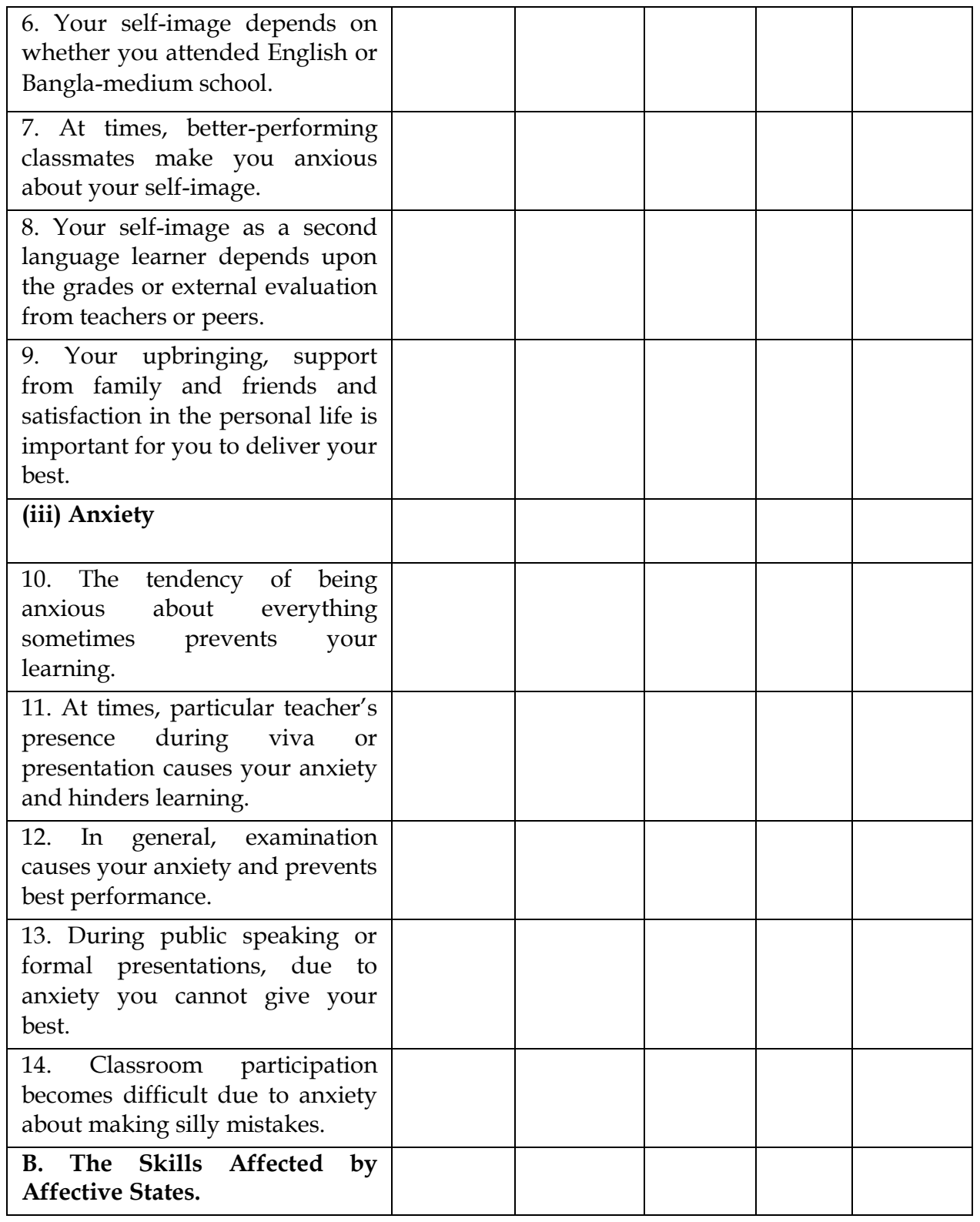




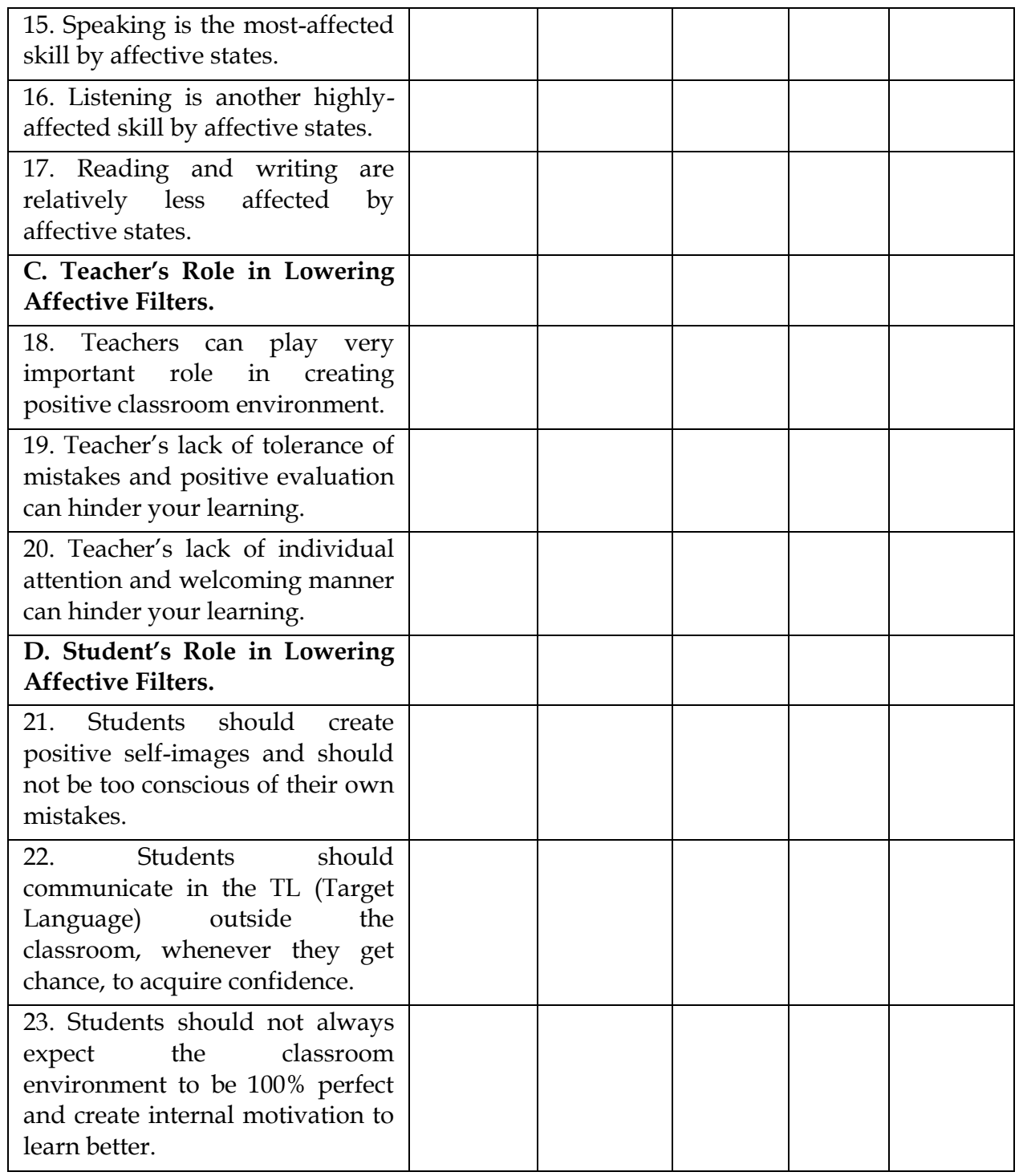


24. How would you rate your English proficiency?
1) Very bad
2) Bad
3) Average
4) Good
5) Very good

25. Do you think you will be capable of learning English better, if affective filters (low motivation, little self-confidence, high anxiety) are lowered in the classroom?

- Yes

- No

WHY? 